\title{
Transparência como limitação à corrupção e estímulo ao desenvolvimento local no estado de Mato Grosso
}

\author{
Transparency as a limitation to corruption and stimulation of local development \\ in the state of Mato Grosso \\ Transparencia como limitación a la corrupción y estímulo al desarrollo local en \\ el estado de Mato Grosso
}

\author{
Karina Nunes da Silva Santos ${ }^{1}$ \\ Ivana Aparecida Ferrer Silva ${ }^{1}$
}

Recebido em: 07/05/2019; revisado e aprovado: 29/07/2019; aceito em: 31/10/2019

DOI: http://dx.doi.org/10.20435/inter.v22i3.2557

\begin{abstract}
Resumo: A transparência nas decisões governamentais impede a proliferação da corrupção ao proporcionar o controle social pelos atores locais que prezam pelo fluxo contínuo do desenvolvimento local. Nesse cenário, o objetivo deste estudo consiste em identificar as ferramentas de transparência que auxiliam no combate à corrupção e no desenvolvimento local do estado de Mato Grosso. Para o alcance do objetivo central, foi necessária a consulta à literatura, a identificação das ferramentas de transparência existentes e, finalmente, a análise de como as ferramentas de transparência contribuem para a redução da corrupção e o desenvolvimento local. Em síntese, a metodologia utilizada em relação aos objetivos é a pesquisa exploratória e, em relação aos procedimentos técnicos, é a pesquisa documental, por meio da coleta de dados secundários cujos relatórios estatísticos são predominantes. Os resultados encontrados apontam que as ferramentas de transparência geram impactos positivos universais, indicados para quaisquer unidades da Federação, haja vista que estimulam o desenvolvimento local ao combaterem a corrupção. Uma vez que elevam a legitimidade política, o destino correto dos recursos públicos e a consciência de coletividade, efetivam o empoderamento e o controle social, impulsionando o compromisso dos governantes com o exercício pleno da ética e da integridade.
\end{abstract}

Palavras-chave: transparência; corrupção; desenvolvimento local; impactos.

Abstract: The transparency in government decisions prevents the proliferation of corruption by providing social control by local actors who cherish the continued flow of local development. In this scenario, the objective of this study is to identify the transparency tools that help in the fight against corruption and in the local development of the state of Mato Grosso. To reach the central objective, it was necessary to consult the literature, identify the existing transparency tools and, finally, analyze how transparency tools contribute to reducing corruption and local development. In summary, the methodology used in relation to the objectives is exploratory research and, concerning the technical procedures, is the documentary research, through the collection of secondary data whose statistical reports are predominant. The results show that the transparency tools generate universal positive impacts, indicated for any units of the Federation, since they stimulate the local development in combating corruption, either because they effectuate the empowerment and the social control, or because they impel commitment of the rulers with the full exercise of ethics and integrity, in order to prevail political legitimacy, the correct destination of public resources and the conscience of collectivity. Keywords: transparency; corruption; local development; impacts.

Resumen: La transparencia en las decisiones gubernamentales impide la proliferación de la corrupción al proporcionar el control social por los actores locales que aprecian el flujo continuo del desarrollo local. En este escenario, el objetivo de este estudio consiste en identificar las herramientas de transparencia que auxilian en el combate a la corrupción y en el desarrollo local del estado de Mato Grosso. Para el alcance del objetivo central, fue necesaria la consulta a la literatura, la identificación de las herramientas de transparencia existentes y, finalmente, el análisis de cómo las herramientas de transparencia contribuyen para la reducción de la corrupción y el desarrollo local. En síntesis, la metodología utilizada en relación a los objetivos es la investigación exploratoria y, en relación a los procedimientos técnicos, es la investigación documental, a través de la recolección de datos secundarios, cuyos informes estadísticos son predominantes. Los resultados encontrados apuntan que las herramientas de transparencia generan impactos positivos universales, indicados para cualquier unidad de la Federación, considerando que estimulan el desarrollo local al combatir

\footnotetext{
${ }^{1}$ Universidade Federal de Mato Grosso (UFMT), Cuiabá, Mato Grosso, Brasil.
} 
la corrupción, sea por el hecho de efectivizar el empoderamiento y el control social, sea por el hecho de impulsar el compromiso de los gobernantes con el ejercicio pleno de la ética y de la integridad, a fin de prevalecer la legitimidad política, el destino correcto de los recursos públicos y la conciencia de colectividad.

Palabras clave: transparencia; corrupción; desarrollo local; impactos.

\section{INTRODUÇÃO}

A transparência é um instrumento essencial para o combate à corrupção, ao mesmo tempo em que contribui para o desenvolvimento local. No Brasil, em meio às exigências populares ao longo da história, que suscitavam a construção de um Estado mais descentralizado e menos protecionista, surgem as ferramentas de transparência, efetivando, assim, o pleno exercício do controle social pelos atores locais, apesar de não se saber ao certo o número real de cidadãos que se valem das ferramentas (MOURA, 1998; PEREIRA, 2002; PAGOTTO, 2010; RIGUEIRO, 2014; OLIVEIRA; BORGES, 2018).

A participação popular, no entanto, é suprimida pela incidência da corrupção, já que fere o processo democrático e a justiça social, causa o descrédito dos governantes, estimula a desconfiança social, aumenta a desigualdade na distribuição de renda, debilita as instituições públicas, impede o desenvolvimento local e, consequentemente, reduz o nível de crescimento das nações. O desenvolvimento local, sensível às boas práticas de governança na prestação dos serviços públicos, torna-se fundamental para a inserção dos atores sociais no exercício da cidadania. Por meio da transparência, tem-se, então, o empoderamento social e a inibição dos atos corruptos (PEREIRA, 2002; VIEIRA-MELO, 2010; ROSA, 2004; ROSE-ACKERMAN, 2005; LAMBSDORFF, 2007; LOUREIRO; TEIXEIRA; PRADO, 2008; PAGOTTO, 2010; GAMBI; MORESCO; GONZÁLEZ, 2014; AFONSO, 2015).

Devido à corrupção e a outras causas, em janeiro de 2019, foi aprovado o decreto de calamidade financeira do estado de Mato Grosso, contudo o governo federal não reconheceu a situação, alegando, principalmente, a existência de um aumento na arrecadação fiscal. Isso não significa necessariamente que tais recursos sejam direcionados corretamente, julgando que o estado enfrenta escândalos sucessivos de corrupção transnacional, sendo retratado, inclusive, nos jornais El País e The New York Times e, portanto, merecendo destaque nesta pesquisa. Além disso, os dados encontrados sobre seu índice de desenvolvimento não retratam necessariamente a realidade, pois, em relação à educação, investigar a qualidade é essencial e, no que se refere à renda, é importante ponderar sobre a sua concentração.

Nesse cenário, é relevante o surgimento de estudos que evitem a mera abordagem de conceitos isolados, haja vista que o entrelaçamento de conceitos múltiplos proporciona maior aprofundamento e interpretação do fenômeno investigado (GIL, 2008). A transparência, quando associada às práticas anticorrupção e ao desenvolvimento local, possibilita a cobertura de situações contemporâneas, evidenciadas, sobretudo, em instituições públicas, sendo necessária a compreensão das interligações entre os referidos acontecimentos, no intuito de haver a prevenção de danos e a potencialização de benefícios.

O problema norteador desta pesquisa é apresentado a seguir: como as ferramentas de transparência impactam a corrupção local? Sendo assim, o objetivo geral consiste em identificar as ferramentas de transparência que auxiliam no combate à corrupção e no desenvolvimento local do estado de Mato Grosso. Para tanto, foram realizadas consultas à literatura sobre a transparência, 
a corrupção e o desenvolvimento local; identificadas as ferramentas de transparência existentes; e, por último, buscou-se analisar como as ferramentas de transparência contribuem para a redução da corrupção e o desenvolvimento local.

Em relação à sua estrutura, o estudo inicia-se com esta introdução e, em seguida, o referencial teórico compreende a transparência, a corrupção e o desenvolvimento local. A terceira seção é a metodologia, que possui contribuições tanto da pesquisa exploratória quanto da pesquisa documental, de modo que os resultados são apresentados e discutidos somente na próxima seção. E, por fim, a pesquisa é finalizada com as considerações finais.

\section{REFERENCIAL TEÓRICO}

\subsection{Transparência, corrupção e desenvolvimento local}

Durante o período pós-guerra, o Estado enfrentou incontáveis movimentos sociais que exigiam a redução do protecionismo e, consequentemente, o aumento da liberdade de mercado. Esses movimentos impulsionaram reformas estatais que viabilizaram a liberdade positiva ${ }^{2} \mathrm{da}$ sociedade. A partir da era pós-industrial, entretanto, uma simples reforma não seria suficiente para a estabilização econômica dos países, sendo necessária uma reconstrução profunda do Estado, que, além do sentido social, passaria a considerar o sentido econômico e político do mercado. Dessa forma, uma parcela da responsabilidade pública é transferida para o setor privado, principal potencializador das relações comerciais (PEREIRA, 2002).

As decisões cabíveis à máquina pública tendem a retardar a entrega de resultados para a população, devido ao excesso de procedimentos burocráticos. A princípio, a adoção da burocracia não abarcava a transparência nos processos decisórios, contribuindo para a discrição desenfreada sobre informações e para a inexistência do controle social (PAGOTTO, 2010). No âmbito privado, por sua vez, a troca de informações era extremamente valorizada como propulsora da alavancagem das organizações. Em meio aos conflitos éticos, as informações confidenciais, quando descobertas pela concorrência por métodos escusos, geraram a ampliação da competitividade no setor e, desde o século XX, grandes crises financeiras foram também provocadas. Diante disso, a transparência detalhada é fundamental, tendo em vista que a mera transparência dos atos não é sinônimo de comunicação bem-sucedida de informações, cuja publicação deve conter explicações (MENANTEAU, 2012).

Como um instrumento público, a transparência é um processo que envolve o exercício da cidadania no que se refere ao conhecimento das decisões estatais, contribuindo principalmente para a efetivação das políticas públicas. A transparência também é um dos resultados gerados pelo processo de democratização, compreendendo dimensões sociais, culturais, econômicas, financeiras, administrativas (GAMBI; MORESCO; GONZÁLEZ, 2014; AFONSO, 2015). Nesse contexto, a sua importância no âmbito público é reafirmada no momento em que se torna um instrumento de prevenção à corrupção.

$\mathrm{Na}$ antiguidade, é possível constatar a corrupção em diversas situações, seja em conflitos por território, seja por alimentos. É um fenômeno que resiste na sociedade por meio de sua incorporação por culturas distintas. Enquanto Bonifácio e Ribeiro (2016) apontam que a

\footnotetext{
${ }^{2}$ É importante enfatizar que tanto a liberdade positiva quanto a liberdade negativa não são excludentes, coexistindo principalmente em sociedades democráticas.
} 
corrupção pode ser uma infração, um comportamento calculado ou até mesmo parte de um sistema normativo, Pereira (2002) defende que ela é sinônimo de propina e gestão ineficiente e ineficaz, concretizando-se em práticas antissociais. Se, por um lado, a transparência origina-se da democracia, por outro, a corrupção é multicontextual.

$\mathrm{O}$ assunto em questão é negligenciado no meio social. Em um regime que admite a liberdade ideológica, a participação popular é obrigatória, ou seja, os cidadãos devem prezar pelos seus direitos. Contudo, ao assumir a forma de subornos, fraudes, peculato, a proliferação da corrupção causa sensação de impunidade, afastando o interesse da sociedade na resolução do problema. Embora muitos governos possuam elites que legislam em causa própria, comprovando que a corrupção é um fracasso institucional, os governantes são essenciais no combate, uma vez que haja demandas por mais transparência na tomada de decisões de interesse coletivo (ROSEACKERMAN, 2005; RAUSCH; SOARES, 2010).

A inibição de atos corruptos é realizada com base em incentivos ou penalidades que visam evitar: danos à sociedade; entraves à participação popular nas deliberações públicas; redução da transparência; afrontas contra a forma de governo adotada; e violação do bem coletivo. $O$ fenômeno pode inviabilizar o desenvolvimento de quaisquer nações ao adaptar-se aos diferentes regimes de governo. Além disso, a privação de educação, saúde ou cultura, primordiais para a dignidade humana, gera a inexistência do senso de coletividade e, consequentemente, a incidência da corrupção. Em síntese, quanto maior a organização de um país, mais bem-sucedido é o combate à corrupção (ROSA, 2004; LAMBSDORFF, 2007).

É importante enfatizar que, no século XX, o desenvolvimento dos países era analisado somente a partir de indicadores econômicos, sendo incluídos, mais tarde, indicadores de outra natureza, como os indicadores sociais e os indicadores ambientais. Assim como a corrupção, o desenvolvimento é um fenômeno complexo de ser mensurado com exatidão, possuindo inúmeros desdobramentos, entre eles, os achados sobre o desenvolvimento local (RIGUEIRO, 2014).

O debate sobre o desenvolvimento local tem início na década de 1980, quando o Estado enfrentava uma crise relacionada à necessidade de descentralização de responsabilidades, situação que incluiu os governos locais na concretização das políticas públicas. Nesse cenário, as instituições estatais federais e privadas recebem as empresas locais como parceiras. De modo geral, o desenvolvimento local compreende a própria localidade como um espaço de atores que geram a sua evolução (MOURA, 1998). Para Amartya-Sen (2010), o desenvolvimento abarca liberdades que assumiriam a forma de processos e oportunidades, sendo os processos correspondentes à liberdade de escolha nas decisões e as oportunidades como a liberdade para o alcance dos objetivos e um possível empoderamento.

A definição atual do desenvolvimento local foi incorporada, a princípio, pelo bengalês Yunus, fundador do Grameen Bank, primeiro banco do mundo a fornecer microcrédito e detentor do Prêmio Nobel da Paz 2006, devido às suas iniciativas de empoderamento da população local. Na visão de Yunus (1999), a situação ocorre de fato quando os aspectos socioeconômicos envolvem os indivíduos que permanecem na linha de pobreza, ou seja, há de se considerar a base da pirâmide. A ideia de que gerar empregos resulta na inclusão social torna-se obsoleta do ponto de vista do desenvolvimento local da base da pirâmide, que direciona a capacidade das pessoas para o autodesenvolvimento. 


\subsubsection{Impactos na sociedade}

A transparência do Estado brasileiro tem um longo histórico que perpassa crises e reformas simplistas, cuja superação é evidenciada em meados dos anos 1990, devido à busca pela recuperação da autonomia e da capacidade política do Estado. Com o fim da ditadura militar em 1985, a pressão popular que exigia o aumento do nível de transparência do país foi atendida por meio da consolidação do controle social e da possibilidade de acesso à informação pelos cidadãos (PEREIRA, 2002).

A transparência possibilita tanto o controle da corrupção quanto a boa governança. Entretanto, se o nível educacional de determinada região e, consequentemente, a integração social forem baixas, a compreensão das publicações governamentais estará comprometida e a transparência causará pouco impacto no país (ROSE-ACKERMAN, 2005). Embora boa parte da literatura classifique a transparência como instrumento de importância notória para a prevenção e o combate à corrupção, vale ressaltar que os seus benefícios ainda são abrangentes, merecendo o devido aprofundamento (LAMBSDORFF, 2007).

Nos estados brasileiros, a transparência no setor público é representada por ferramentas específicas que podem ser utilizadas pelos cidadãos, entre elas: os portais eletrônicos de transparência; as ouvidorias; as políticas de governança; o Serviço de Informações ao Cidadão (SIC); a própria Lei de Acesso à Informação (LAI) e a Lei de Responsabilidade Fiscal (LRF), que estabelecem instrumentos e diretrizes a serem adotadas; o Cadastro Nacional de Empresas Inidôneas e Suspensas (CEIS); o Cadastro Nacional de Pessoas Punidas (CNEP); o Cadastro de Expulsões da Administração Federal (CEAF); o Cadastro de Entidades Privadas Sem Fins Lucrativos Impedidas (CEPIM); e o Sistema de Gestão de Convênios e Contratos de Repasse (SICONV). Essas ferramentas proporcionam ao cidadão o controle dos recursos de interesse coletivo (PEREIRA, 2002; BRASIL, 2013).

Enquanto os portais de transparência prezam pela publicidade de informações, as ouvidorias atuam como canais de reclamações e denúncias. As políticas de governança fomentam boas práticas de gestão, sendo eficazes no combate à corrupção. Se, por um lado, o SIC é um canal de exigências diretas, por outro, a LAl e a LRF são ferramentas originárias dos portais de transparência e do próprio $\mathrm{SIC}$, tendo em vista que o teor normativo estimula iniciativas de transparência e gera o equilíbrio fiscal. Em relação ao CEIS, CNEP, CEAF e CEPIM, tais elementos referem-se às consequências punitivas das relações comerciais entre a administração pública, o setor privado e os administrados. Ademais, o SICONV, última ferramenta, permite o acompanhamento das transferências de recursos federais via convênio para os entes federativos e entidades privadas sem fins lucrativos (BRASIL, 2013).

A transparência é positiva apenas quando utilizada para fins éticos, sendo conveniente apresentar seus principais impactos na sociedade. De acordo com Pagotto (2010), a transparência inibe o efeito oculto da corrupção, suprimindo decisões com fins escusos e facilitando o acesso dos cidadãos às informações. Em países com pouca consciência coletiva, o seu papel, conforme Rose-Ackerman (2005), é pressionar os gestores e as instituições internacionais para que se comprometam com os meios éticos de gestão, evitando-se, com isso, ações lesivas contra o patrimônio e contra os cidadãos.

Procedimentos transparentes limitam a atuação dos governantes, contribuindo para a prevalência da probidade e a erradicação da corrupção. A partir do momento em que há o 
efetivo controle social, a legitimação e a credibilidade dos próprios gestores são alcançadas. A transparência ainda reduz a tolerância ao suborno e, consequentemente, ocasiona o equilíbrio das contas públicas, considerando-se que a tolerância mínima remete ao aumento de cobranças populares para que haja qualidade nos gastos. Ao consolidar os preceitos democráticos de um povo, desencadeia a reestruturação do Estado, incentiva a prestação de contas e gera o empoderamento da população. Desse modo, a transparência proporciona a comunicação entre governantes e governados e o cumprimento das políticas públicas (PEREIRA, 2002; LAMBSDORFF, 2007; LOUREIRO; TEIXEIRA; PRADO, 2008; MENANTEAU, 2012; GAMBI; MORESCO; GONZÁLEZ, 2014; AFONSO, 2015).

A corrupção é definida como prejudicial por boa parte dos teóricos e, conforme a figura 1, o Brasil encontra-se em situação alarmante, tendo em vista que possui variações no Índice de Percepção da Corrupção (IPC), divulgado pela Transparency International, organização responsável pelo combate à corrupção no plano nacional e internacional, assim como a Controladoria-Geral da União lida com o fenômeno no plano nacional. No índice mais recente, o país alcançou a sua pior colocação, indicando a necessidade de controlar a corrupção, principalmente quando os seus impactos são identificados.

Figura 1 - Histórico das posições do Brasil no IPC, desde a sua fundação

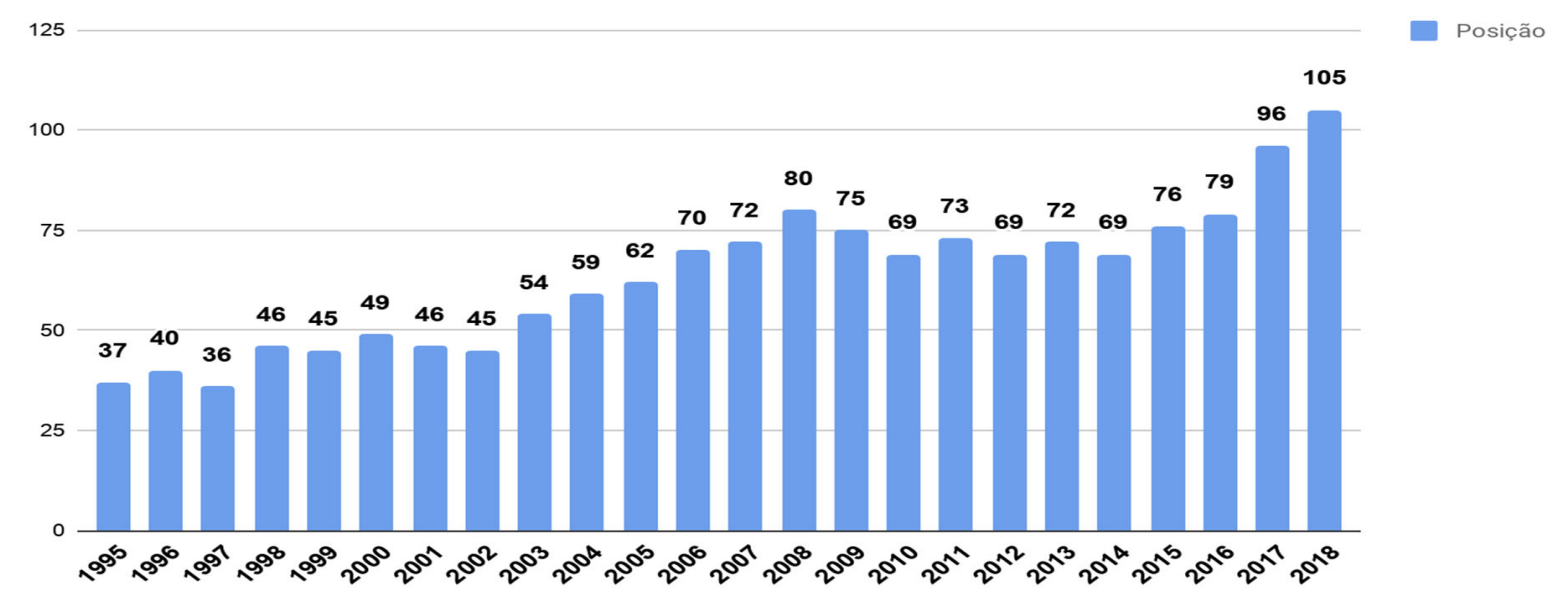

Fonte: Elaboração própria a partir da Transparency International (2019).

Nesse caso, diante dos inúmeros prejuízos causados pela corrupção, cabe destacar seus impactos negativos. A corrupção por si só representa o fracasso institucional, a redução do bemestar social, o desperdício de recursos em meio à má gestão, a perda do potencial de crescimento, o entrave às reformas que favorecem o povo e a criação de programas e projetos que ferem o interesse coletivo (ROSE-ACKERMAN, 2005). No Brasil e em demais nações emergentes, a corrupção limita o atendimento às necessidades primárias de grande parte da população, disseminando a sensação de injustiça social (VIEIRA-MELO, 2010; SACRAMENTO; PINHO, 2018). O fenômeno é um entrave a qualquer eixo do desenvolvimento, seja ele social, econômico, ambiental. Assim, acarreta a desigualdade, comprometendo até mesmo a ordem republicana, a democracia e a dignidade humana.

A distorção das decisões de interesse público estagna de tal modo o comércio, a ciência e o avanço tecnológico, que a corrupção passa a ser o principal motivo para o corte de recursos 
destinados a essas áreas. A corrupção direciona também recursos e benefícios para áreas supérfluas, afastando investimentos devido à falta de credibilidade e legitimidade atribuída ao Estado. O fenômeno causa a degradação ambiental, o aumento da pobreza, a banalização do serviço público, a elevação do nível de desconfiança do povo, a ausência de efetivação das políticas públicas, danos à arrecadação fiscal e problemas orçamentários (VIEIRA-MELO, 2010; ROSA, 2004). A corrupção, portanto, rejeita a adoção de procedimentos transparentes e retarda a evolução das nações.

Nesse contexto, o desenvolvimento local apresenta quatro dimensões: capital humano, capital social, capital empresarial e capital ambiental. Os conceitos referentes ao desenvolvimento local abrangem, de certo modo, o potencial dos atores sociais em proporcionarem melhorias na localidade a qual pertencem, situação que demanda qualificação profissional, preservação cultural e ambiental e bem-estar social. Embora a sua compreensão seja simples, abarca uma infinidade de heranças culturais. Logo, tal conceito não se restringe a uma localidade específica (RIGUEIRO, 2014; OLIVEIRA; BORGES, 2018).

No que se refere aos seus impactos, o desenvolvimento local nada mais é do que um desenvolvimento participativo que protege a identidade cultural ao gerar atividades produtivas e renda, ao valorizar o conhecimento local, ao preservar os recursos necessários à sobrevivência, ao fomentar a interação social e ao melhorar a qualidade de vida da população (MAIA; SIQUEIRA; ROZENDO, 2017; TUMA; MARQUES; SOARES, 2017; OLIVEIRA; BORGES, 2018). Em síntese, possibilita o atendimento das necessidades básicas dos atores locais levando em consideração o capital humano, o capital social, o capital empresarial e o capital ambiental (RIGUEIRO, 2014).

\section{PROCEDIMENTOS METODOLÓGICOS}

Os processos de construção deste estudo são inerentes à abordagem qualitativa, responsável por garantir a investigação de fenômenos dignos de análise e interpretação. A pesquisa qualitativa possibilita experiências de interação com base na seleção convencional de participantes ou de documentos qualitativos, ou seja, documentos públicos ou privados, institucionais ou não, detentores de alto grau de informações. Diante disso, esse tipo de abordagem ou pesquisa suscita a questionamentos, análises e registros de apoio para as futuras interpretações (CRESWELL, 2010).

Quanto aos seus objetivos, a pesquisa é exploratória e uma de suas finalidades é justamente a aproximação do pesquisador aos fenômenos selecionados. No que se refere aos procedimentos técnicos, a pesquisa é predominantemente documental, com algumas características da pesquisa bibliográfica, uma vez que ambas as pesquisas possibilitam a aquisição de materiais de diversas fontes, diferindo apenas no tratamento analítico das informações, que ocorre somente na pesquisa bibliográfica (GIL, 2008).

A coleta de dados desenvolveu-se no mês de abril de 2019 e apreciou documentos secundários oficiais, prevalecendo a utilização de relatórios estatísticos sobre o estado de Mato Grosso, no intuito de ser realizada, posteriormente, a análise interpretativa dos dados. Além disso, grande parte das fontes utilizadas foi extraída a partir da base de dados SciELO. Entre os critérios adotados para a seleção, exigiu-se apenas que os termos transparência, corrupção e desenvolvimento local estivessem presentes no título. 


\section{APRESENTAÇÃO E DISCUSSÃO DOS RESULTADOS}

\subsection{Caracterização situacional do estado de Mato Grosso}

Nos estudos de Ferrer Silva (2012), o estado de Mato Grosso, localizado na região CentroOeste, consolida-se a partir de um processo de construção histórica em que prevaleceram os interesses econômicos estimulados por instituições públicas sobre os saberes locais e as particularidades territoriais. Além disso, a investigação sobre a aderência de alguns segmentos industriais no que se refere à inovação sustentável aponta que as estruturas produtivas do estado desfavoreceram o desenvolvimento endógeno, acarretando o aumento das desigualdades sociais. A inovação sustentável no estado, nesse caso, é quase inexistente. Tal situação comprova que o volume de empresas e o capital existentes em uma região não representam necessariamente a sua evolução, tendo em vista que, caso o conhecimento nativo e as características locais sejam depreciados, o próprio desenvolvimento é comprometido, mantendo-se restrito a determinada parcela da sociedade. Nesse contexto, faz-se importante a desmistificação dos dados apresentados posteriormente. Embora o estado detenha enorme potencial de crescimento, os dados não possuem o nível de aprofundamento adequado para informar quais são as suas deficiências, já que apenas parte da população é alvo de pesquisa.

Em relação ao Produto Interno Bruto (PIB) do estado, a variação em volume no ano de 2016 apresentou queda (-6,3\%), levando-o à 25a posição entre os estados. Contudo, entre 2015 e 2016, Mato Grosso conquistou maior participação no PIB nacional, com avanço de 0,2 ponto percentual, devido a fatores como a elevação de preços de bens agrícolas, a redução de preço de adubos e fertilizantes e os avanços da indústria e do comércio. No que se refere ao desempenho em volume do PIB, que compreendeu o período entre 2002 e 2016, foi considerado o segundo estado com maior crescimento, apesar da ocorrência de quedas momentâneas, sendo o seu PIB per capita alavancado cerca de 5,2 vezes (IBGE, 2018). Com base nessas informações, a região seria elencada como bem-sucedida se não houvesse o fator de compensação negativa, ou seja, a comercialização e a industrialização tendem a um descontrole econômico. Enquanto a prosperidade mantém-se nas relações comerciais, os oligopólios são fortalecidos e, consequentemente, os benefícios não são repassados para a população. Tal fato é estimulado devido à supremacia da cultura do enriquecimento, contribuindo cada vez mais para o aumento de organizações interessadas somente em seu próprio crescimento, excluindo os atores locais e degradando os recursos naturais do estado.

Acerca do desenvolvimento humano averiguado entre os anos de 1991 e 2010, todos os estados da região Centro-Oeste passaram a abarcar um alto nível de desenvolvimento. Mato Grosso, por sua vez, recebe destaque por manifestar crescimentos sucessivos no Índice de Desenvolvimento Humano Municipal (IDHM) em contraste com os estados vizinhos, com 0,276 de incremento total. Embora esse resultado seja positivo quando comparado às dimensões de renda, longevidade e educação, são evidenciadas deficiências. Em termos de renda, educação e do próprio IDHM total, o estado se mantém alguns pontos abaixo da média brasileira. A dimensão longevidade possui 0,821 ponto em relação a 0,816 ponto do Brasil, sendo superior, portanto, a este (ORGANIZAÇÃO DAS NAÇÕES [ONU], 2016). Contudo ressalta-se que esse índice apresenta estimativas, não representando a realidade integralmente. A versão de 2015 do Programa Internacional de Avaliação de Estudantes (PISA), diretamente ligado à educação, indica o desempenho dos estudantes em ciências, leitura e matemática. Conforme o índice 
educacional que demonstra a dificuldade por país e unidade da Federação, os estudantes do estado de Mato Grosso geralmente enfrentam alto nível de dificuldade em ciências, leitura e matemática, mantendo-se com pontuação similar à média brasileira (BRASIL, 2016).

O IDHM apresenta estimativas que merecem cautela na análise. Mato Grosso e quaisquer outros estados apresentam concentração de renda, fato desconsiderado pelo IDHM, assim como a qualidade de ensino ofertada à população. A renda concentrada em uma região, quando apreciada em sua totalidade, direciona os resultados de uma pesquisa a uma sociedade igualitária, apresentando um resultado equivocado. Acerca da educação, se a sua qualidade é refletida pelo total de investimentos, é conveniente ressaltar que, para diversos noticiários locais, os desvios de recursos são predominantes justamente na área da educação e da saúde. Assim, as carências do estado são mascaradas à medida que dados estatísticos são apresentados sem a ênfase necessária aos fatores negligenciados. Não é possível afirmar que certa região tem alto nível de desenvolvimento se todas as dimensões envolvidas não forem exploradas. Da mesma forma, ao inserir Mato Grosso junto à média do país, o PISA utiliza-se de meios obsoletos para averiguar o grau de educação no país e nas unidades federativas, pois somente três áreas são objeto de análise. Há de se falar que a literatura internacional já apresenta a visão de que a educação deve ser múltipla, desenvolvendo as inteligências múltiplas dos indivíduos. Meios rígidos educacionais que possuem qualidade duvidosa, como acontece com todos os estados brasileiros, desestimulam a continuidade dos estudos.

Recentemente, o governo de Mato Grosso declarou situação de calamidade financeira, entrando na lista das unidades federativas de mesma situação, porém o governo federal optou por não reconhecer tal declaração, devido ao enorme potencial de arrecadação fiscal do estado. Essa crise é ocasionada, provavelmente, pelos diversos $\operatorname{casos}^{3}$ de corrupção no estado descobertos nos últimos anos, atingindo predominantemente áreas essenciais relacionadas à prestação de serviços públicos. Entre os efeitos negativos da crise, a área da saúde, por ser a mais sensível em termos econômicos e financeiros, obtém inúmeros prejuízos, e esse fato evidencia um histórico amplo de descaso. Dessa maneira, os Indicadores e Dados Básicos de 2012 (IDB), fornecidos pelo Sistema Único de Saúde (SUS), estabelecem séries históricas de investimentos demasiadamente moderados, que ferem não apenas o princípio de acesso universal à saúde, mas também o princípio da dignidade humana (BRASIL, 2021). Nota-se que a área da saúde ainda carece de políticas mais rígidas acerca de sua efetivação pelo Estado, tendo em vista que os governantes geralmente priorizam outras situações, como a autorização para reformas em órgãos públicos, por exemplo.

Segundo o IDB de 2012, os gastos do governo do estado com ações e serviços públicos de saúde, entre 2000 e 2012, apresentaram uma evolução gradual com o passar dos anos. No entanto os gastos ainda são insuficientes, tendo em vista que, em 2010, para cada 1.000 habitantes, havia apenas um médico. Além de haver a necessidade de mais investimentos na contratação de profissionais de saúde para a ampliação do atendimento, há ainda carências quanto ao número de leitos hospitalares disponíveis à população, pois, nos anos de 2002, 2005 e 2009, períodos divulgados pelo IDB, para cada 1.000 habitantes, havia a possibilidade de inexistência de um leito hospitalar (BRASIL, 2021).

\footnotetext{
${ }^{3}$ Segundo a página do G1 Mato Grosso (ANJOS, 2016; MORAES, 2018), os casos de maior repercussão transnacional foram as prisões do ex-governador Silval Barbosa, ao desviar mais de 1 bilhão de reais do estado, e do ex-presidente da Assembleia Legislativa do Estado de Mato Grosso, José Riva, conhecido como o "maior ficha-suja do país" e réu em mais de 100 ações judiciais.
} 
Diante dos resultados encontrados, mesmo que apresente níveis sucessivos de crescimento, Mato Grosso é um estado carente em termos de desenvolvimento, educação e saúde. Não se pode afirmar que é desenvolvido, pois, desde a sua formação, os avanços ocorrem em setores específicos, prevalecendo-se os oligopólios. As áreas da educação e da saúde não detêm excelência devido aos investimentos rasos e, aliado a isso, ainda há o desvio desses investimentos, que já são escassos. Nessas circunstâncias, o estado necessita de uma reestruturação em suas políticas públicas, de modo que o capital entrante não fique restrito ao poder de alguns, e os benefícios sejam distribuídos à população. Essa mudança exige a pressão dos atores locais para que estes sejam incluídos no processo de desenvolvimento.

\subsection{Ferramentas de transparência e impactos}

A universalidade da transparência aponta para a existência de impactos em grande e em pequena escala. Após a apresentação das ferramentas de transparência apontadas pela literatura, constatou-se que todas possuem vínculo com o estado de Mato Grosso. O fato de haver ferramentas federais reforça a sua inclusão junto aos demais estados. Ademais, em relação às particularidades de cada unidade federativa, enquanto alguns criam os seus próprios mecanismos de transparência, como é o caso de Mato Grosso, outros adotam iniciativas somente em atendimento às exigências da União. Sendo assim, resgatando as conceituações e abordagens vistas anteriormente, são apresentados no Quadro 1 os impactos fundamentais da transparência, da corrupção e do desenvolvimento local.

Quadro 1 - Relação dos impactos identificados na literatura

\begin{tabular}{|c|c|}
\hline \multicolumn{2}{|c|}{ Transparência } \\
\hline $\begin{array}{l}\text { - Inibição da corrupção } \\
\text { - Supressão de decisões escusas } \\
\text { - Facilidade no acesso à informação } \\
\text { - Pressão para o comprometimento com a ética } \\
\text { - Controle da probidade dos governantes } \\
\text { - Efetivação do controle social } \\
\text { - Fornecimento de legitimidade e credibilidade } \\
\text { - } \text { aos gestores }\end{array}$ & $\begin{array}{l}\text { - Equilíbrio das contas públicas } \\
\text { - Aumento de cobranças populares para haver } \\
\text { - } \text { - Consulidade nos gastos } \\
\text { - Desencação dos preceitos democráticos } \\
\text { - Incentivo à prestação de contas } \\
\text { - Empoderamento da população } \\
\text { - Comunicação bilateral } \\
\text { - Cumprimento de políticas públicas }\end{array}$ \\
\hline \multicolumn{2}{|c|}{ Corrupção } \\
\hline $\begin{array}{l}\text { - Representação do fracasso institucional } \\
\text { - Redução do bem-estar social } \\
\text { - Desperdício de recursos e má gestão } \\
\text { - Perda do potencial de crescimento nacional } \\
\text { - Entrave às reformas que favorecem o povo } \\
\text { - Criação de programas e projetos contra o } \\
\text { - interesse coletivo } \\
\text { - Limitação ao atendimento das necessidades } \\
\text { - } \text { - Obstimárias e sensação de injustiça social } \\
\text { - Prevalência da desigualdade } \\
\text { - Comprometimento da ordem republicana, da } \\
\text { - democracia e da dignidade humana }\end{array}$ & $\begin{array}{l}\text { - Estagnação dos setores econômicos } \\
\text { - } \text { Direcionamento de recursos e benefícios para } \\
\text { - Afastamento de investimentos } \\
\text { - Falta de credibilidade e legitimidade do Estado } \\
\text { - Degradação ambiental } \\
\text { - Aumento da pobreza } \\
\text { - Banalização do serviço público e elevação do } \\
\text { - nível de desconfiança do povo } \\
\text { - Redusência de efetivação das políticas públicas } \\
\text { - Geração do nível de arrecadação fiscal } \\
\text { - Rejeição à transparemas orçamentários } \\
\text { - Retardamento da evolução das nações }\end{array}$ \\
\hline
\end{tabular}




\section{Desenvolvimento local}

- Desenvolvimento participativo

- Proteção à identidade cultural

- Geração de atividades produtivas e renda

- Valorização do conhecimento local
- Preservação de recursos para a sobrevivência

- Interação social

- Qualidade de vida

- Atendimento das necessidades básicas do povo

Fonte: Elaboração própria.

Já no Quadro 2, houve a verificação somente dos principais impactos causados pelas ferramentas de transparência, apesar do fato de que praticamente a totalidade de seus impactos suprime a corrupção de alguma forma, fomentando o desenvolvimento local ao mesmo tempo. Vale destacar que a corrupção e o desenvolvimento local do estado de Mato Grosso apresentam os mesmos impactos devido ao teor universal da transparência, sendo o seu efeito aplicável tanto a mecanismos benéficos quanto a mecanismos prejudiciais.

Quadro 2 - Ferramentas de transparência e seus impactos na corrupção e no desenvolvimento local

\begin{tabular}{|c|c|}
\hline Ferramentas de transparência & $\begin{array}{l}\text { Principais impactos no combate à corrupção e no } \\
\text { desenvolvimento local }\end{array}$ \\
\hline Portal de transparência & Efetivação do controle social \\
\hline Ouvidoria & Inibição da corrupção \\
\hline Políticas de governança & Pressão para o comprometimento com a ética \\
\hline Serviço de Informações ao Cidadão (SIC) & Empoderamento da população \\
\hline Lei de Acesso à Informação (LAI) & Facilidade no acesso à informação \\
\hline Lei de Responsabilidade Fiscal (LRF) & Incentivo à prestação de contas \\
\hline $\begin{array}{l}\text { Cadastro Nacional de Empresas Inidôneas e } \\
\text { Suspensas (CEIS) }\end{array}$ & $\begin{array}{l}\text { Aumento de cobranças populares para haver } \\
\text { qualidade nos gastos } \\
\text { Incentivo à prestação de contas }\end{array}$ \\
\hline Cadastro Nacional de Pessoas Punidas (CNEP) & Pressão para o comprometimento com a ética \\
\hline $\begin{array}{l}\text { Cadastro de Expulsões da Administração } \\
\text { Federal (CEAF) }\end{array}$ & Pressão para o comprometimento com a ética \\
\hline $\begin{array}{l}\text { Cadastro de Entidades Privadas Sem Fins } \\
\text { Lucrativos Impedidas (CEPIM) }\end{array}$ & $\begin{array}{l}\text { Aumento de cobranças populares para haver } \\
\text { qualidade nos gastos } \\
\text { Incentivo à prestação de contas }\end{array}$ \\
\hline $\begin{array}{l}\text { Sistema de Gestão de Convênios e Contratos } \\
\text { de Repasse (SICONV) }\end{array}$ & $\begin{array}{l}\text { Controle da probidade dos governantes } \\
\text { Equilíbrio das contas públicas } \\
\text { Aumento de cobranças populares para haver } \\
\text { qualidade nos gastos }\end{array}$ \\
\hline
\end{tabular}

Fonte: Elaboração própria.

Os portais de transparência contribuem para a plena efetivação do controle social, que detém força suficiente para reduzir a corrupção e incluir os atores sociais nos processos decisórios locais. As ouvidorias, por sua vez, são as instâncias superiores responsáveis de fato por utilizar os instrumentos cabíveis para a inibição da corrupção. Essas medidas bastam para que o fluxo 
das atividades locais retorne à normalidade. Quanto às políticas de governança, ao CNEP e ao CEAF, mostram-se como ferramentas de pressão que geram cobranças para o comprometimento dos governantes com a ética, que causa benefício mútuo quando exercida, sendo favorável ao desenvolvimento e eficaz contra práticas corruptas.

Aliada à ética, o SIC físico e eletrônico, iniciativa proposta pela LAI, cuja responsabilidade primária é facilitar o acesso à informação, contribui para o empoderamento da população local e o maior controle dos atos públicos, evitando-se, assim, a corrupção. Enquanto a LRF, o CEIS e o CEPIM têm a função primordial de incentivar a prestação de contas, o CEIS e o CEPIM, juntamente do SICONV, têm também o papel de estimular cobranças da população para a qualidade nos gastos. Ainda cabe ao SICONV proporcionar o controle da probidade dos governantes e do equilíbrio das contas públicas pelos cidadãos. Ações que envolvam a prestação de contas, a qualidade no direcionamento de recursos públicos, a probidade no exercício das atribuições e o equilíbrio financeiro são empecilhos básicos à permanência da corrupção no âmbito local. Uma vez que os impactos da corrupção sejam impedidos em determinado meio social, a participação popular prevalece e, consequentemente, ocorre o desenvolvimento da localidade.

No estado de Mato Grosso, algumas das ferramentas identificadas geram questões que contrastam com os dados expostos anteriormente. Nesse contexto, o Portal da Transparência do Governo Federal evidencia duas instituições no Relatório de Pedidos de Acesso à Informação e Solicitantes. Desde junho de 2012 até o início de abril de 2019, a Universidade Federal de Mato Grosso (UFMT) recebeu 918 pedidos de 678 solicitantes, sendo que 911 solicitações já haviam sido respondidas. No mesmo período, o Instituto Federal de Mato Grosso (IFMT) recebeu 760 pedidos de 488 pessoas, respondendo a 758 solicitações.

No que diz respeito às políticas de governança, pela Lei n. 10.691, de 5 de março de 2018, foi instituído o Programa de Integridade Pública do Governo do Estado de Mato Grosso, no intuito de aumentar a lisura e a integridade dos órgãos, cabendo ao Gabinete de Transparência e Combate à Corrupção proporcionar o devido apoio. Em alguns casos, não há de se falar em apoio, mas sim em sanções e penalidades devido à gravidade dos atos. Entre as ferramentas de cunho punitivo, há o CEIS, o CNEP, o CEPIM e o CEAF. As empresas de Mato Grosso detêm 265 sanções no CEIS, uma sanção no CNEP e 95 sanções no CEPIM. Além disso, há 180 servidores punidos com a expulsão da Administração Federal. Por fim, acerca do SICONV, três municípios do estado estão inadimplentes quanto aos precatórios judiciais, são eles: Nova Monte Verde, Pontal do Araguaia e Porto dos Gaúchos.

Dessa forma, uma vez que a transparência pode ser considerada uma resposta dos atores locais no combate à corrupção, o desenvolvimento local beneficia-se das políticas anticorrupção. O estado de Mato Grosso e as demais unidades federativas, ao valerem-se das ferramentas de transparência já elencadas, contribuem para o surgimento de uma sociedade com maior senso de coletividade, impedindo a proliferação da injustiça social nas comunidades até então excluídas e isoladas pelos governantes corruptos.

\section{CONSIDERAÇÕES FINAIS}

Este estudo se propôs a identificar as ferramentas de transparência que auxiliam no combate à corrupção e no desenvolvimento local do estado de Mato Grosso, atendendo efetivamente aos objetivos propostos e, inclusive, complementando os resultados com dados oficiais, a fim de 
aproximar-se ao máximo da realidade dos achados. Ressalta-se que as ferramentas apresentadas incluem a Lei de Acesso à Informação (LAI) e a Lei de Responsabilidade Fiscal (LRF), ambas consideradas norteadoras das demais ferramentas.

Esses instrumentos são implementados no momento em que o Brasil adere efetivamente às medidas de responsabilização dos gestores públicos, estimulando, consequentemente, o empoderamento social. O controle social passa a ser ancorado sob a ótica do desenvolvimento local, permeando o interior dos estados e municípios (YUNUS, 1999; PEREIRA, 2002; VIEIRA-MELO, 2010; ROSA, 2004; ROSE-ACKERMAN, 2005; LAMBSDORFF, 2007; LOUREIRO; TEIXEIRA; PRADO, 2008; PAGOTTO, 2010; GAMBI; MORESCO; GONZÁLEZ, 2014; AFONSO, 2015).

Assim, entre os resultados, destaca-se que a transparência enquanto resposta à corrupção, tanto no estado de Mato Grosso quanto nos demais estados, fomenta o desenvolvimento local pelo simples fato de gerar impactos de cunho universal em benefício aos atores locais, incentivando a fiscalização popular das decisões públicas e dos governantes propensos à corrupção. A adoção das ferramentas de transparência existentes, portanto, contribui para o empoderamento social igualitário, reforçando a consciência de coletividade.

As principais limitações do processo de construção da pesquisa permeiam o excesso de índices socioeconômicos e a pouca divulgação deles, gerando buscas incessantes por dados oficiais. Todavia tais dificuldades foram compensadas devido à vasta literatura e disponibilização de revistas especializadas sobre os três assuntos investigados, conferindo certo grau de aprofundamento.

Portanto recomenda-se que os futuros pesquisadores, a princípio, construam objetivos sólidos e realizáveis no prazo de que dispõem, tendo em vista que a literatura é extensa. Ainda, recomenda-se a aplicação deste estudo às instituições públicas e privadas, para que o pesquisador detenha uma visão holística dos impactos in loco da transparência, da corrupção e do desenvolvimento local.

\section{REFERÊNCIAS}

AFONSO, Almerindo Janela. Recuo ao cientificismo, paradoxos da transparência e corrupção em educação. Educação e Pesquisa, São Paulo, v. 41, n. especial, p. 1313-26, dez. 2015.

AMARTYA-SEN. Desenvolvimento como liberdade. Tradução de Laura Teixeira Motta. São Paulo: Companhia das Letras, 2010.

ANJOS, Lislaine. Ação contra ex-deputado de MT réu em mais de 100 processos prescreve. G1 Mato Grosso, Cuiabá, jun. 2016. Disponível em: http://g1.globo.com/mato-grosso/noticia/2016/06/acao-contraex-deputado-de-mt-reu-em-mais-de-100-processos-prescreve.html. Acesso em: 30 abr. 2019.

BONIFÁCIO, Robert; RIBEIRO, Ednaldo. Corrupção e participação política no Brasil: diagnósticos e consequências. Revista Brasileira de Ciência Política, Brasília, n. 20, p. 7-42, maio/ago. 2016.

BRASIL. Ministério da Saúde. Departamento de informática do SUS. Indicadores e dados básicos para a saúde: Brasil 2012. Datasus, [s.I.], 2021. Disponível em: http://tabnet.datasus.gov.br/cgi/idb2012/matriz. htm. Acesso em: 30 abr. 2019.

BRASIL. Ministério da Educação. Brasil no PISA 2015: análises e reflexões sobre o desempenho dos estudantes brasileiros. Brasília-DF: Fundação Santillana, INEP, Ministério da Educação, 2016. 
BRASIL. Ministério da Transparência e Controladoria-Geral da União [CGU]. Manual da lei de acesso à informação para Estados e Municípios. Brasília-DF: CGU, 2013.

CRESWELL, John W. Projeto de pesquisa: métodos qualitativo, quantitativo e misto. Tradução de Magda Lopes. 3. ed. Porto Alegre: Artmed, 2010.

FERRER-SILVA, Ivana Aparecida. Inovação sustentável na indústria do estado de Mato Grosso: setores de alimentos e madeireiro (1970-2012). 2012. 232 f. Tese (Doutorado em Desenvolvimento Sustentável do Trópico Úmido) - Universidade Federal do Pará, Belém, PA, 2012.

GAMBI, Mauricio Olavarría; MORESCO, Hernán García; GONZÁLEZ, Claudio Allende. Transparencia en funcionarios públicos chilenos. Documentos y Aportes en Administración Pública y Gestión Estatal (DAAPGE), Santa Fe, ano 14, n. 23, p. 71-92, 2014.

GIL, Antonio Carlos. Métodos e técnicas de pesquisa social. 6. ed. São Paulo: Atlas, 2008.

LAMBSDORFF, Johann Graf. The institutional economics of corruption and reform: theory, evidence, and policy. New York: Cambridge University Press, 2007.

LOUREIRO, Maria Rita; TEIXEIRA, Marco Antônio Carvalho; PRADO, Otávio. Construção de instituições democráticas no Brasil contemporâneo: transparência das contas públicas. Organizações \& Sociedade, Salvador, v. 15, n. 47, p. 107-19, out./dez. 2008.

MAIA, Zildenice Matias Guedes; SIQUEIRA, Elisabete Stradiotto; ROZENDO, Cimone. Desenvolvimento local e qualidade de vida na percepção de agricultoras no Assentamento Mulunguzinho em Mossoró-RN. Polis Revista Latinoamericana, Santiago, v. 16, n. 46, p. 295-319, 2017.

MENANTEAU, André. Transparencia y comunicación financiera. Cuadernos del Centro de Estudios en Diseño y Comunicación, Buenos Aires, ano 12, n. 40, p. 97-106, abr. 2012.

MORAES, Lidiane. Ex-governador de MT confessa ter 'se apropriado' de R\$ 1 bilhão em dinheiro público. G1 Mato Grosso, Cuiabá, fev. 2018. Disponível em: https://g1.globo.com/mt/mato-grosso/noticia/exgovernador-de-mt-confessa-ter-se-apropriado-de-r-1-bilhao-em-dinheiro-publico.ghtml. Acesso em: 30 abr. 2019.

MOURA, Suzana. A gestão do desenvolvimento local: estratégias e possibilidades de financiamento. Organizações \& Sociedade, Foz do Iguaçu, v. 5, n. 12, p. 37-57, mai./ago. 1998.

OLIVEIRA, Lina Yule Queiroz; BORGES, Pedro Pereira. O direito à cidade e o desenvolvimento local como base para a humanização do espaço urbano. Interações, Campo Grande, v. 19, n. 4, p. 739-55, out./dez. 2018.

ORGANIZAÇÃO DAS NAÇÕES UNIDAS [ONU]. Programa das Nações Unidas para o desenvolvimento. Human Development Report 2016. Nova Iorque: ONU, 2016. Disponível em: http://hdr.undp.org/sites/ default/files/2016_human_development_report.pdf. Acesso em: 29 abr. 2019.

PAGOTTO, Leopoldo Ubiratan Carreiro. O combate à corrupção: a contribuição do direito econômico. 2010. 409 f. Tese (Doutorado em Direito) - Universidade de São Paulo, São Paulo, SP, 2010.

PEREIRA, José Matias. Reforma do Estado e transparência: estratégias de controle da corrupção no Brasil. In: CONGRESO INTERNACIONAL DEL CLAD SOBRE LA REFORMA DEL ESTADO Y DE LA ADMINISTRACIÓN PÚBLICA, 7., 8-11 out. 2002. Lisboa: CLAD, 2002. Disponível em: https://core.ac.uk/download/ pdf/33529140.pdf. Acesso em: 18 abr. 2019. 
IBGE. Sistema de contas regionais: Brasil 2016. Rio de Janeiro: IBGE, 2018.

RAUSCH, Rita Buzzi; SOARES, Maurélio. Controle social na administração pública: a importância da Transparência das Contas Públicas para inibir a corrupção. Revista de Educação e Pesquisa em Contabilidade, Brasília-DF, v. 4, n. 3, p. 23-43, 2010.

RIGUEIRO, Inês Cipriano. Desenvolvimento local sustentável: uma abordagem à sustentabilidade dos projetos de empreendedorismo social. 2014. Dissertação (Mestrado em Intervenção Social, Inovação e Empreendedorismo) - Universidade de Coimbra, Coimbra, 2014.

ROSA, Márcio Fernando Elias. Corrupção como entrave ao desenvolvimento. Revista do Tribunal Regional Federal da 1므 Região, Brasília-DF, v. 16, n. 8, p. 17-34, ago. 2004.

ROSE-ACKERMAN, Susan. The challenge of poor governance and corruption. Revista Direito GV, São Paulo, v. 1, n. especial, p. 207-66, 2005.

SACRAMENTO, Ana Rita Silva; PINHO, José Antonio Gomes. Combate à corrupção no Brasil: identificando entraves à luz da versão revisitada da teoria da modernização. Revista Interdisciplinar de Gestão Social, Salvador, v. 7, n. 1, p. 113-34, jan./abr. 2018.

TRANSPARENCY INTERNATIONAL. Transparency, 2019. Corruption perceptions index. Disponível em: https://www.transparency.org/research/cpi/overview. Acesso em: 29 abr. 2019.

TUMA, Raquel Lage; MARQUES, Heitor Romero; SOARES, Maria Elisabeth Alves Mesquita. Feria del Cerrado, Goiânia: la participación social para el desarrollo local. Interações, Campo Grande, v. 18, n. 1, p. 191-202, jan./mar. 2017.

VIEIRA-MELO, Clóvis Alberto. Corrupção e políticas públicas: uma análise empírica dos municípios brasileiros. 2010. 230 f. Tese (Doutorado em Ciência Política) - Universidade Federal de Pernambuco, Recife, PE, 2010.

YUNUS, Muhammad. The grameen bank. Scientific American, Nova lorque, v. 281, n. 5, p. 114-19, nov. 1999.

\section{Sobre as autoras:}

Karina Nunes da Silva Santos: Graduanda no curso de Bacharelado em Administração na Universidade Federal de Mato Grosso (UFMT). Bolsista do programa de Iniciação Científica (PIBIC) na UFMT. E-mail: kahnunessantos@gmail.com, Orcid: http://orcid.org/0000-0001-8586-7401

Ivana Aparecida Ferrer Silva: Doutora em Desenvolvimento Sustentável do Trópico Úmido pela Universidade Federal do Pará (UFPA). Mestre em Administração pela Universidade Federal do Rio Grande do Norte (UFRN). Bacharel em Administração pela Universidade Federal de Mato Grosso (UFMT). Professora adjunta da faculdade de Administração e Ciências Contábeis na UFMT. E-mail: ivanaferrer21@yahoo.com.br, Orcid: http://orcid.org/0000-0002-4972-3504 
